\title{
A New Model for Analysis of Customer Interaction Activities of City Tours Providing Organizations: Implementation to Selective Tours of Sofia, Bulgaria
}

\author{
Elena Petkova ${ }^{\mathrm{A}}$ \\ Received: November 2019 | Accepted: April 2020 \\ DOI: $10.5937 /$ turizam\%v-24756
}

\begin{abstract}
The aim of the article is to present a model of the activities of the city tour provider organizations, involving relations with customers (tourists). The activities involving customer interactions include relations before, during and after the city tours. The model has been implemented to analyze the city tours of Sofa, Bulgaria. The results revealed that tours in Sofia are characterized by a high degree of interactivity between personnel and customers, and customers themselves, involvement of partners and intensive use of technologies.
\end{abstract}

Keywords: City Tours, Model, Customers, Providers, Sofia, Bulgaria

\section{Introduction and literature review}

In the last few years, a significant development of tourism in the capital city of Bulgaria - Sofia - is observed. There is a growth in both tourism supply and tourism demand. Among the various newly developed tourism products targeted at the increasing number of tourists, innovative city tours appeared. Instead traditional tour operators, non-government organizations or private companies running other businesses as well provide these tours. Although there is a significant number of city tours with many tourists, only a limited number of studies analyze these tours. A thorough study of the activities of the organizations that provide city tours concerning specifically their relations with customers (tourists) has not been performed yet.

City tours in other regions of the world have been explored from different perspectives. Specifically, aspects concerning the relations of the city tours providing organizations with tourists have been studied too. In this regard, Ratz (2016) claims that the tours are characterized by knowledge, enthusiasm and personalized approach of the guides. Besides guides, significant is the role of the customers themselves in the tour. Larsen and Widtfeldt Meged (2013) regard guides and tourists as mutual depending co-producers of the guided tours. Wynn (2010) adds that during the tours the guide and the group bond in a learning community, and create

A Sofia UniversitySt. Kliment Ohridski, Faculty of Geology and Geography, Tourism Department, 15 Tsar Osvoboditel blvd, 1504 Sofia, Bulgaria; Corresponding author: epetkova@gea.uni-sofia.bg 
the 'mutual attachment' between tourists and the city. Hallin and Dobers (2012) confirm that city guides and guided tours determine the way cities are understood. According to Guano (2015) guides help transform a place into a city worth visiting by creatively exploiting its 'hiddenness'.

Some authors emphasize on the role of the new technologies and especially the social media in the interactions of the organizations' personnel with tourists and among tourists themselves. Andron (2018) claims that the dissemination of information about the tours happens through digital communication platforms. According to Widtfeldt Meged and Zillinger (2018) organizations use social media, which creates direct links between the company and the consumers based on trust among peers.

Scientists also explore relationships with partners and the revenue model of the organizations that provide city tours. In this regard, del Pilar et al. (2017) observed that in order to market their products, free walking tour companies usually develop joint ventures with other entities like cafes, hotels, etc. Concerning the payment model, the same authors claim that free walking tours are a way of introducing tourists to a wide range of payment products of the tour provider organizations.

Specifically, some publications concerning tourism mention city tours of Sofia. According to Dogramadjieva et al. (2018b), in the last few years, there is an expansion of the various city tours of Sofia, which try to show the city to the tourists in a different and informal way. Dogramadjieva et al. (2018a) point out that a number of representatives of the tourism businesses in Sofia claim that the appearance of the free city tours is a positive trend. An article by Dogramadjieva et al. (2019) presents the results of an in-depth study of the city tours in Sofia. It outlines the following key determinants of a valuable tourist experience: the guide's skills and personality; enjoyable learning and deeper understanding; local experience and discovery; fun and entertainment; and freedom and flexibility. ${ }^{1}$

Scientists often regard city tours as some type of innovation (Ratz, 2016; Del Pilar et al., 2017; Widtfeldt Medeg, Zillinger, 2018). In addition to their statements, we claim that city tours are innovation not only at organizational but also at destination level. In this regard, recently we performed a more extensive and in-depth study concerning the innovativeness of selected city tours in Sofia (Petkova et al., 2019). For that study, we applied the service innovation model developed by den Hertog et al. (2010). Based on the results of the study of the city tours of Sofia (Petkova et al., 2019), a conclusion was drawn that the tours bring a novelty through the utilization of previously unemployed elements of the urban environment of Sofia city, but they are much more innovative in terms of customer interaction, delivery system, business partnerships and revenue models applied.

The study (Petkova et al., 2019) confirmed that the model of den Hertog et al. (2010) could be successfully applied in the field of tourism and particularly in academic studies of guided tours as a specific tourist service. The challenges in implementing the model refer to difficulties in making a concise distinction among separate dimensions of innovativeness, since they overlap and penetrate one another due to the complex process of generating and putting into practice new ideas (Petkova et al., 2019).

1 Although it is not the topic of the present study, we should mention that the organizations providing the city tours in Sofia and in the other cities of the world are often criticized as they challenge the legal system of the countries. These tours are usually not provided by licensed tour operator companies. Instead of authorized tourist guides they used volunteers. The tour provider organizations often do not pay taxes, etc. 


\section{Methods and data}

In order to overcome the last challenge, we developed and applied a new model. The model is based on some aspects and statements expressed in already-developed techniques, namely:

1. the classical model of front office and back office activities of service business (Zomerdijk, de Vries, 2007);

2. the model of the customer-dominant logic of service of Heinonen et al. (2010);

3. object orientation approach (Jacobson et al., 1995) and

4. the service innovation model developed by den Hertog et al. (2010).

According to the first model, services consist of front office, which includes customer contacts activities and back office, which includes non-customer contact activities on a service delivery system (Zomerdijk, de Vries, 2007). Therefore, all activities of service organizations can be divided in front office activities and back office activities that we think should be analyzed separately. In this article, we present a model just of front office or customer interaction activities.

Heinonen et al. (2010) introduced a new perspective on the roles of customers and companies in creating value by outlining a customer - based approach to service. According to their approach, customers experience value before, during and after the service (Heinonen et al., 2010). Therefore, interactions that take place with customers can be divided in activities before, during and after service. In this regard, our model should allow us to analyze front office activities before, during and after service.

Jacobson et al. (1995) present a technique for modelling the workings of a company named the object orientation. According to that model, we see a company as a system, which consists of a large number of objects (its components). Objects contain information about their properties - attributes - and can offer behavior towards other objects (associations/ interactions) (Jacobson at al., 1995). That technique allows us to describe companies' activities (interactions among objects) and the participants (subjects/ objects) involved. Therefore, in our model we should outline customer interactions, which take place before, during and after the service, as well as the participants involved.

The model of den Hertog et al. (2010) outlines six dimensions where service innovation can take place in a business, namely:

1. new service concept;

2. new customer interaction;

3. new business partnership

4. new revenue model;

5. new delivery system (personnel, organization, culture);

6. new delivery system (technology) (den Hertog et al., 2010).

These dimensions are included in our model as components and interactions on the service system.

Thus, in order to develop a comprehensive, detailed and applicable model for the analysis of customer interactions of a service company, we should outline front office activities before, during and after the service like interaction among the components of the service system. We derive these interactions and components from the model or den Hertog et al. (2010) and they include personnel, partners, technologies, organization, payment, etc. We think that our 
model is suitable for analyzing a service system, in particular its customer interaction activities, components and participants involved.

The aim of the article is to present a model of the activities of the city tour provider organizations involving relations with customers (tourists) (i.e. front office activities). Therefore, activities, which the organizations perform without being necessary to interact with customers (i.e. back office activities), are not included. The activities involving customer interactions include relations before, during and after the tours. The model can be applied for both - an overall evaluation and the assessment of certain aspects of service like their degree of innovativeness though an in-depth analysis both at organizational and at destination level. The model is shown in Figure 1.

The application of the model requires a thorough examination of interactions with customers, which can be divided in activities before, during and after the tours (service). The organizational, performance and payment aspects of the tours should be assessed. An exploration of the relations of city tours provider organizations with their customers (tourists) is also required. The analysis should also include the prerequisites, which are created by tour providers for efficient interactions between customers and partners, as well as among customers themselves.

The service organizations' personnel provide customer service. However, sometimes partner organizations are also included in customer service. During the tours, the personnel of the organizations (tourist guides) interact with customers by themselves or along with the staff of partner organizations in order to provide service. Interactions with potential and new customers take place also before and with real customers - also after the tours. In addition, in contemporary world the technology also has an important role to play in the relations between businesses and customers. Technologies have a significant role during all phases of interactions with tourists. The model could be used to evaluate how organizations manage that part of their activities where interactions with customers take place.

We implemented the model to analyze the city tours of Sofa, Bulgaria. We studied city tours in Sofia provided by five organizations (two NGOs and three business companies), mainly aimed at foreign visitors. The selection of these suppliers is based on their TripAdvisor ranking. We included only providers ranked among the first 12 out of all 107 offers in Sofia in April

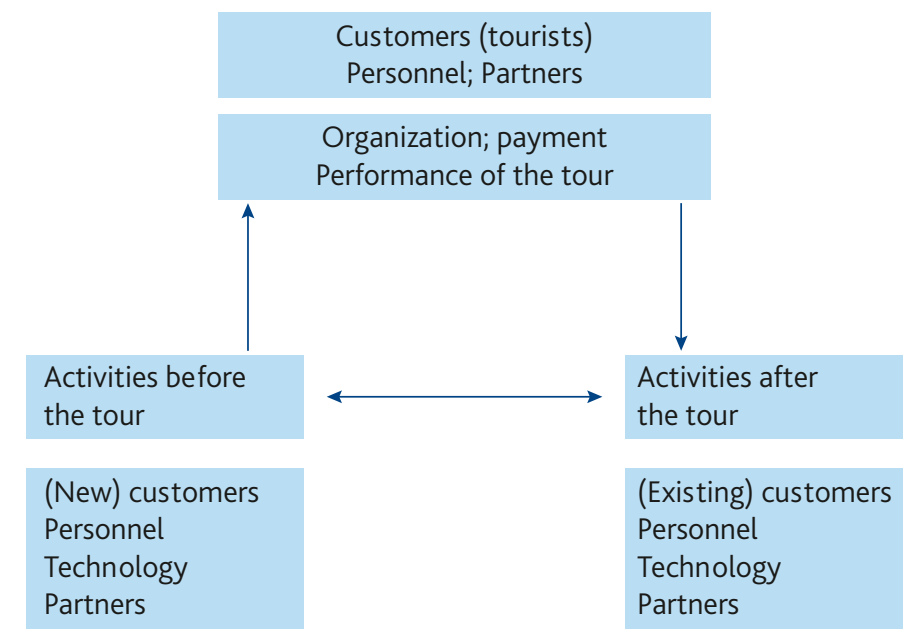

Figure 1. A model for the analysis of the city tours providing organizations activities involving relationships with touristsm 
2019 are included. As some providers offer several different city tours of Sofia, the total number of studied tours is thirteen. Almost half of them (6) are "free" (tip-based) and the rest are offered on a fixed price. Only two of the tours are introductory in content while the rest are targeted at specific areas of interest such as communist heritage, traditional culture, local cuisine, nightlife, street art, contact with nature, etc. (Table 1).

Table 1. Studied Sofia city tours

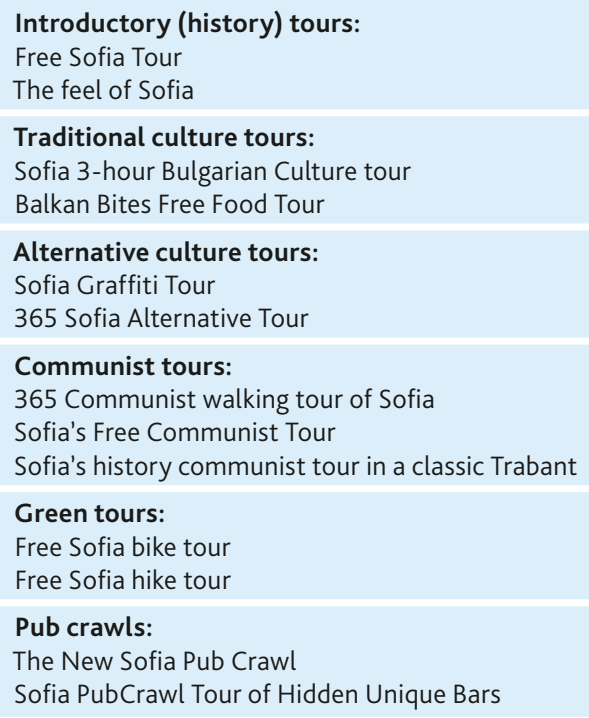

The study presents a qualitative analysis of the information available on the websites of the studied supplier organizations, which is completed by semi-structured interviews with four managers or owners and four tourist guides. The interviews were conducted in the period April - June 2019. There were separate questionnaires for managers and guides, which contained open questions. The questionnaires were prepared by a research team and included questions that allow important aspects of the tours (characteristics, organization, relationships among tourist guides and tourists during the tours, etc.) to be explored. The main difference between both questionnaires was the way of formulating the questions in compliance with specific competences and perspectives of the interviewees. The interviewers aimed to interview tourist guides and managers from all of the studied organizations that provide the tours ranked high according to TripAdvisor ranking. In most cases, two interviewers conducted the interviews so that they could later complement each other's notes. Information was categorized based on the presented model.

\section{Organizers' activities during the tours}

\section{Characteristics and performance of the tours}

The main purpose of the tours of Sofia is to present the city to the world in a different and attractive way. The city tours focus on various topics and activities, such as getting an idea of the city, culture and visits of cultural sights, hidden and unique places, local traditions, history, 
street art, local cuisine, nightlife and entertainment, adventure, active lifestyle, contacts with nature, etc. The purpose of the free tours is to present a brief introduction to the city, while customers are encouraged to join the other (often paid) tours of the companies.

The tours are usually organized in advance. Routes are preliminary defined but sometimes there is a room for change by the guide - e.g. in case of bad weather and construction works, according to the needs of tourists, etc. In some tours, the decision about which sites (e.g. food and beverage establishments) to be included depends on latest's ability to receive a group at a particular day and time. Several guides accompany large groups or the group is divided into smaller groups led by different guides, who go through different routes. Paid (especially private) tours are characterized by greater flexibility than free ones. Customers can choose route, means of transport, time, date, meeting point, to be taken by the hotel, etc.

\section{Payment of the tours}

There are both 'free' and paid tours. Many tours are 'free' but if the customers wish, they may give a tip or make a donation. That gives them a sense of independence. Customers are free to choose whether to pay or not. They can pay the amount, which they think the service is worth, i.e. they determine the price. Besides, they pay after the tour and not in advance, which would oblige them to stay until the end regardless of whether they liked the tour or not. Therefore, unlike the traditional pricing model where suppliers set the price according to their costs, hereby customers determine it according to their perception of service quality. Besides being favorable to the customers, the model of 'free tours' is also beneficial to the organizing company, as the guides will try to give their best and if the customers are very pleased, they might give a much larger amount of money than the organizer would set as a price. Thus, the tour provider has an incentive to improve quality in order to meet customer requirements. In addition, a satisfied customer will purchase other services of the same organization and will recommend it to other people. Thus, customers satisfied with a free tour are likely to buy paid tours from the same organizations. Moreover, organizations partly spent the revenues from donations on charitable causes, which create a favorable public image.

\section{Personnel and customers involvement and interactions}

\section{Characteristics of the tourist guides and tourists}

Tourist guides are often volunteers or free-lancers. ${ }^{2}$ Many guides are students or have another first profession that they are actively practicing. According to the specifics of the tours, sometimes they are also professionals at the fields of history, architecture or archeology or mountain guides. Sometimes specific technical skills are required like bicycle riding skills, language skills, etc. Particularly important are the personal skills of the guides - communication and

2 In Bulgaria, a person should be licensed to practice as tourist guide and be registered on the list of authorized tourist guides, part of the National Tourist Register (see, https://ntr.tourism.government.bg/Web/Certificates. nsf/enguides.xsp).

Therefore, there is a concern by the authorized tourist guides that volunteers used for specific tours in Sofia might be working illegally. Besides, the studied city tours provider organizations are often criticized that they do not pay social security taxes for their employees as the tourist guides work as volunteers. 
artistic skills, etc. While some guides are specialized in only one tour, others lead various thematic ones. Some guides even lead tours managed by different organizations. In addition, many managers are practicing guides too.

The providers aim the tours at non-organized tourists. The tourists buy the tour as a separate service not as a package along with accommodation, food, transportation, etc. Tourists who take part in a single tour are usually from different countries and cultures.

\section{Relations between tourists and tourist guides and interactions among tourists themselves}

Communication between tourists and guides during the studied tours is freer and friendlier in comparison with traditional tours. Regarding the information, sometimes the guide decides what, how and when to say to tourists. In some cases, the style of speaking of the guides is very informal; they use humor and freely comment diverging views. Tourist guides express a personal opinion about politics, economy, culture, etc., which appeals to tourists. They try to establish close contacts with tourists and lead casual conversations.

Tourists have the opportunity to be acquainted and communicate with locals - tourist guides, as well as to interact with each other, to communicate with many other tourists in the group - people from different countries. During the tours, people get very close to each other and make friends. The tours involve games, theaters, etc. People know it will be fun.

\section{Involvement of partners}

\section{Involvement of partners in serving the customers}

Partners of tour providing organizations include hotel and restaurant establishments, tour operators, companies offering similar tours, cultural institutions, etc. The aim of the partnerships is either customer service or promotion. The personnel of tour provider organizations work together with the staff of some of the partners to serve tourists.

An interesting example of partnership in terms of serving the customers during the tour is that of the Balkan Bites Free Food Tour. The tour takes tourists to several different partner restaurants in the city center, whose personnel provides the service of offering the tourists to taste sample food for free while the tourist guide of the city tour organization lead the tourists through those places and explains the peculiarities of the local cuisine and culture.

\section{Promoting services and goods of partner organizations}

In the above example, Balkan Bites Free Food Tour promotes local food business, since people often return to the restaurants to have meals later. Promotion of other partners also takes place during the tours. An example is the little booklet of the 365 Association, which guides give to the tourists during every tour. It contains information about services of their partners that are thus promoted to a large number of independent travelers. 


\title{
Organizers' activities before and after the tours informational and promotional acrivities
}

\author{
Involvement of partners and technology
}

The tour providers promote themselves through fliers, which they distribute in partner accommodation facilities. In addition, the studied city tour providers are well aware that people are increasingly searching and buying from the Internet, and constantly monitor current technological trends and new technical opportunities. The studied organizations have created user-friendly web sites. The web sites present the information in an attractive way. The data is easy to reach. The texts are short and various applications, such as pictures, maps, calendars, videos, etc. are available. The information concerns aspects, such as when the tours are performed, what are the routes and duration, how the tourists should get prepared, etc. Tour organizers work with Google to be in the front positions of the search engine. Tours organizers also use blogs and try to be on as many platforms as possible, such as Google maps, Air Bnb, Get your Guide, To-Do List of FST, Inspider, etc.

\section{Providers-to-customers and customers-to-customers communication through technology}

Prior to and after the tours intensive providers-to-customers, customers-to-providers and customers-to-customers communication takes place through social networks and web platforms. The websites present recognitions of the tours, such as Best Attraction or a Certificate of Excellence from TripAdvisor. The websites of the organizations offer links to the latest reviews in social media like TripAdvisor, Facebook, Twitter, Instagram, YouTube, etc. The organizations intensively promote the use of social networks by their customers where they can publish their reviews and read other people's reviews. Tourists trust positive reviews and other customers' recommendations more than traditional adverts.

\section{Opportunities provided for reservation activities}

Services can be booked in advance on-line or made available on site. It allows customers to join last minute, providing flexibility according to their needs. On some websites, there are options for buying tours from e-shops with selecting the tour parameters, tracking orders, etc.

\section{Conclusion}

In this article, a model for analysis of customer interaction activities of city tour providing organizations was revealed. It includes relations between organizations' personnel and customers and involvement of partners and technology in service before, during and after the tours. The model has been applied for the analysis of selective tours of Sofia, Bulgaria. The implication of the model confirmed that the tours in Sofia are characterized by a high degree of interactivity between personnel and customers, involvement of partners and technologies before, during and after the tours and a specific payment system.

Further studies should be concerned with the implication of the model to evaluate specific aspects, such as the innovativeness of the tours in Sofia. The model could also be applied for the evaluation of tours in other cities. It could be adapted and implemented for the evaluation 
of the innovativeness of other tourism services, provided both by individual organizations and at a destination level too.

Besides the recommendations regarding the application of the model, we propose another model to be developed in order to include back office activities of the service organizations and the two models to be combined.

\section{References}

Andron, S. 2018. Selling Streetness as Experience: The Role of Street Art Tours in Branding the Creative City. The Sociological Review 66(5), 1036-1057.

Del Pilar, M., Londono, L., Medina, F. 2017. Free Walking Tour Enterprises in Europe: An Evolutionary Economic Approach. In: Dredge, D., Gyimothy, S. (Ed.) Collaborative Economy and Tourism Perspectives, Politics, Policies and Prospects. Switzerland: Springer International Publishing AG, 129-151

Den Hertog, P., van der Aa, W., de Jong, MW. 2010. Capabilities for managing service innovation: towards a conceptual framework. Journal of Service Management 21(4), 490 - 514.

Dogramadjieva, E., Mitova, R., \& Nikolova, V. 2018a. Qualitative study of local tourism development based on interviews with key informants: the case of Sofia city. Annual of the Sofia University "St. Kliment Ohridski", Faculty of Geology and Geography, Book 2 - Geography 111, 179-202 (in Bulgarian)

Dogramadjieva, E., Nikolova, V., Mitova, R. 2018b. Sofia city as a tourist destination: Recent trends and development drivers. In: Marinov, V., Vodenska, M., Assenova, M., Dogramadjieva, E. (Ed.), Traditions and Innovations in Contemporary Tourism. Cambridge: Cambridge Scholar Publisher, 282-304

Dogramadjieva, E., Petkova, E., Mitova, R. (2019). Innovative guided tours of Sofia city as a tourist experience: Analysis of customers' on-line reviews. In: M. P. Hrvojevic (Ed.), The Contemporary Trends in Tourism and Hospitality, Get ready for iGeneration, (135-146). Novi Sad: Faculty of Sciences, Department of Geography, Tourism and Hotel Management

Guano, E. 2015. Touring the Hidden City: Walking Tour Guides in Deindustrializing Genoa. City \& Society $27(2), 160-182$.

Hallin, A., \& Dobers, P. 2012. Representation of Space. Uncovering the Political Dimension of Guided Tours in Stockholm. Scandinavian Journal of Hospitality and Tourism 12(1), 8-26.

Heinonen, K., Strandvik, T., Mickelsson, K-J., Edvardsson, B., Sundstrom, E., Andersson, P. (2010). A customer dominant logic of service. Journal of Service Management 21 (4), 531548

Jacobson, I., Ericsson, M., Jacobson, H. (1995). The Objects Advantage: Business Process Reengineering with Object Technology. Addison-Wesley Publishing Company

Larsen, J., Widtfeldt Meged, J. 2013. Tourists Co-producing Guided Tours. Scandinavian Journal of Hospitality and Tourism 13(2), 88-102.

Petkova, E., Dogramadjieva, E., Mitova, R. (2019). New kids in town: Dimensions of the innovativeness of the 'new' city tours of Sofia, Bulgaria. In: M. P. Hrvojevic (Ed.), The Contemporary Trends in Tourism and Hospitality, Get ready for iGeneration, (116-127). Novi Sad: Faculty of Sciences, Department of Geography, Tourism and Hotel Management

Rátz, T. 2016. 'Be global, go local' - innovation and creativity in the development of alternative guiding services in Budapest. Journal of Tourism and Cultural Change 15, 476-489. 
Widtfeldt Meged, J., Zillinger, M. 2018. Disruptive network innovation in free guided tours. Scandinavian Journal of Hospitality and Tourism 18(3), 303-318.

Wynn, J.R. 2010. City Tour Guides: Urban Alchemists at Work. City \& Community 9(2), 145164.

Zomerdijk, L.G., de Vries, J. 2007. Structuring front office and back office work in service delivery systems. An empirical study of three design decisions. International; Journal of Operations \& Production Management 27(1), 108-131.

Internet 1: https://freesofiatour.com/ (2.9.2019)

Internet 2: http://sofiacommunisttour.com/ (2.9.2019)

Internet 3: https://sofiagraffititour.com/ (2.9.2019)

Internet 4: https://sofiagreentour.com/ (2.9.2019)

Internet 5: https://www.thefeelofsofia.com (2.9.2019)

Internet 6: http://www.balkanbites.bg/ (2.9.2019)

Internet 7: http://www.thenewsofiapubcrawl.com/ (2.9.2019) 